\title{
Synthesis of supported catalysts by impregnation and drying using aqueous chelated metal complexes
}

\author{
A. Jos van Dillen, Robert J.A.M. Terörde ${ }^{1}$ Dennis J. Lensveld, \\ John W. Geus, and Krijn P. de Jong* \\ Department of Inorganic Chemistry and Catalysis, Debye Institute, Utrecht University, PO Box 80083, 3508 TB Utrecht, The Netherlands
}

Received 22 July 2002; revised 9 September 2002; accepted 16 September 2002

\begin{abstract}
Work is reviewed on the synthesis of supported metal and metal oxide catalysts using impregnation of an aqueous solution of chelated metal ions followed by drying. The nature of the aqueous solutions of chelated complexes is discussed first. Upon solvent evaporation a steep increase in viscosity is apparent, which inhibits redistribution of impregnated solution upon drying of the support bodies. Furthermore, a gel-like phase is formed that favors high dispersions of the active phase after full drying. Second, several examples are dealt with in some detail, in particular supported iron, nickel, and cobalt-molybdenum catalysts. Finally an overview is presented for metal and metal oxide precursors that can be suitably deposited upon support materials using chelated aqueous metal complex solutions.
\end{abstract}

(C) 2003 Elsevier Science (USA). All rights reserved.

Keywords: Heterogeneous catalysts; Supported catalysts; Catalyst synthesis; Catalyst preparation; Impregnation; Drying; Model catalysts; Chelate; Chelation; Chelated metal ions

\section{Introduction}

Supported metal and metal oxide catalysts comprise the most important class of heterogeneous catalysts in industrial practice. Therefore, the synthesis of supported catalysts is of utmost scientific and industrial importance. For a general overview and background of synthesis methods for supported catalysts we refer to Anderson [1], Geus and Van Veen [2], Che [3a], and De Jong [4]. Briefly, the methods applied widely involve ion exchange [1], homogeneous deposition precipitation [5,6], redox chemistry [4], and chemical vapor deposition [4]. By far the most used synthesis route though involves impregnation of porous support bodies with a solution of the metal (oxide) precursor followed by evaporation of the solvent. The most attractive feature of this route is its simplicity in practical execution on both laboratory and industrial scales. The method is often referred to as impregnation and drying.

\footnotetext{
* Corresponding author.

E-mail address: k.p.dejong@ @ chem.uu.nl (K.P. de Jong).

${ }^{1}$ Present address: Engelhard De Meern B.V., PO Box 19, 3454 ZG De Meern, The Netherlands.
}

Although the practical execution is seemingly simple, the fundamental phenomena underlying impregnation and drying are extremely complex. More often than not the interaction between the metal precursor and the support is limited, thereby allowing redistribution of the active phase over the support body during drying. Since evaporation of the solvent takes place at the exterior of the support particles, capillary flow of solution to its exterior surface may take place, thereby causing production of so-called eggshell catalysts, often with a poor dispersion of the active phase. Pioneering work of Kotter and Riekert [7] has shown that an increase the viscosity of the impregnation solution suppresses outward flow of the solution and leads to more uniform activity profiles over support bodies. Alternative approaches involve very high or very low drying rates [2], but results are of moderate quality only.

Quite unnoticed by the academic catalysis community, an alternative approach to impregnation and drying has been utilized in industrial practice as well as by a few academic groups. The essence of this approach is to use aqueous solutions of multidentate chelated metal complexes. In this review we will discuss the merits of this widely applicable method, which maintains the practical simplicity characteristic of impregnation and drying techniques. It can 
lead to reproducible synthesis routes to supported catalysts, characterized by uniform distributions over support bodies of a highly dispersed active phase. First examples in the academic literature have been published in several $\mathrm{PhD}$ theses supervised by Geus and co-workers. A case in point is the work of Meima et al. [8], which discloses the application of aqueous tin(II)-citrate onto alpha alumina. For completeness we note that ion exchange/adsorption of diamine metal chelates is also a frequently used method for catalyst preparation [3].

In this paper we deal first with the properties of aqueous solutions of multidentate chelated metal ions. It is shown that chelation leads to solutions that are stable over a wide range of $\mathrm{pH}$ and, moreover, increase steeply in viscosity upon evaporation. Second, we describe some fundamental studies using model supports on the interaction of the solutions during drying and the resulting metal (oxide) dispersions. Specific examples are then dealt with, in particular supported iron oxide catalysts (Superclaus process), nickel oxide on ordered mesoporous materials (MCM-41), and cobaltmolybdenum catalysts (hydrodesulfurization), followed by an overview for a wide range of metal (oxide) catalysts.

\section{Properties of aqueous chelated metal ion solutions}

A chelating agent is a molecule with two or more potential electron-pair donor atoms, that can act as a ligand, which attaches itself to a metal ion. Such ligands are described as polydentate and the prefixes di-, tri-, tetra-, penta-, and hexa- are used for two through six bonding positions. Actually, the formation of a metal chelate is a Lewis acid-base reaction. Although acid-base reactions generally are enthalpy driven, chelation of solvated metal ions, as an exception, is governed by a relatively high contribution of the entropy, due to the replacement of many solvent molecules around a metal ion by one chelating ligand. Due to this, most metal chelates exhibit a relatively high stability [9-12].

The chelating agents most commonly used for the preparation of supported catalysts from aqueous solution are citric acid (Cit), nitrilotriacetic acid (NTA), and ethylenediaminetetraacetic acid (EDTA). The Lewis structures of the related anions are given in Fig. 1. The anions of NTA and EDTA contain, respectively, four and six electron-pair donating atoms which, the metal ion included, form five-membered rings. Tridentate coordination of citrate can lead to two six-membered chelate rings, or to one five- and one sixmembered ring [13].

Because of their nature, the chelating ability of the described ligands is closely related to the $\mathrm{pH}$ of the solution. The metal ion/chelate ratio in the complex depends on the overall metal ion/chelate ratio in solution, the presence of other ligands or metal ions, and the $\mathrm{pH}$. A nice example is presented by Medici and Prins, who reported for Mo and $\mathrm{Ni}$, separately and combined, the species present in aqueous solutions containing NTA, as a function of the $\mathrm{pH}$ [14]. Figure 2A gives the thermodynamic prediction for Mo, with $[\mathrm{Mo}]_{\text {tot }}$ and $[\mathrm{NTA}]_{\text {tot }}=1 \mathrm{~mol} / \mathrm{L}$. Figure $2 \mathrm{~B}$ gives the thermodynamic predictions for a system containing the following overall concentrations: $0.5 \mathrm{~mol} / \mathrm{L} \mathrm{Ni}, 5 \mathrm{~mol} / \mathrm{L} \mathrm{NH}_{3}$ and $1 \mathrm{~mol} / \mathrm{L}$ NTA. For the solution containing Mo, Ni, and NTA (ratio $0.5: 1: 1$ ) in $5 \mathrm{~mol} / \mathrm{L} \mathrm{NH}_{3}$ and a $[\mathrm{Mo}]_{\text {tot }}=1 \mathrm{~mol} / \mathrm{L}$ the thermodynamic prediction is presented in Fig. 2C. From this figure it can be concluded that for $\mathrm{pH}$ values exceeding 1 , all $\mathrm{Ni}^{2+}$ ions are complexed to at least one NTA ligand, while the $\left[\mathrm{MoO}_{3}(\mathrm{NTA})\right]^{3-}$ fraction never exceeds a value of 0.5 . Above a $\mathrm{pH}$ level of about $6,\left[\mathrm{Ni}(\mathrm{NTA})_{2}\right]^{4-}$ is formed at the cost of the Mo-NTA complex. Raman spectra support these predictions [14].

In particular Fig. 2B demonstrates that in aqueous solutions, due to the presence of NTA, the precipitation of $\mathrm{Ni}(\mathrm{OH})_{2}$ is shifted to $\mathrm{pH}$ values beyond 12 . In general it can be stated that precipitation of, for example, hydroxides and hydrous oxides of many metal ions can be shifted to appreciably higher $\mathrm{pH}$ levels by addition of chelating agents. This feature is important because, by chelation, the metal precursor can be kept available in solution at a $\mathrm{pH}$ value suitable for impregnation.

Upon gradual removal of the solvent, the viscosity of solutions of metal chelates increases substantially due to gelation. Probably the ligands not only are chelating but also become bridging between the metallic ions, which gives rise to this increased viscosity. This last phenomenon highly affects the results of the drying process of impregnated supports. Not only is migration of the solvent to the external edge of the support particles suppressed, but also crystallization of
A

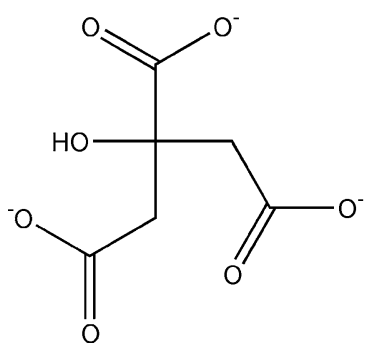

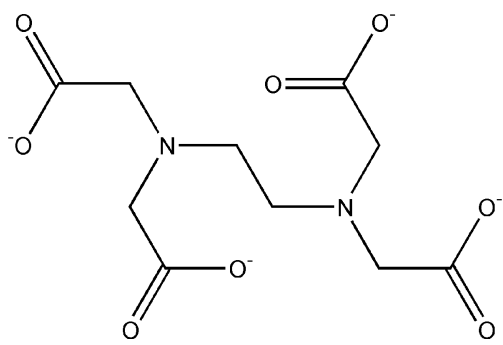

C

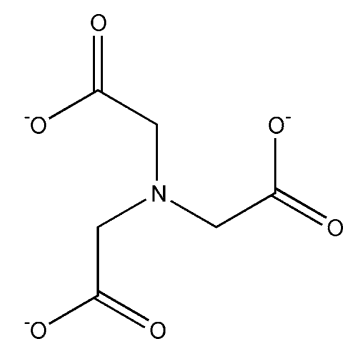

Fig. 1. Anions of citric acid (A), ethylenediamine-tetraacetic acid (B), and nitrilotriacetic acid (C). 

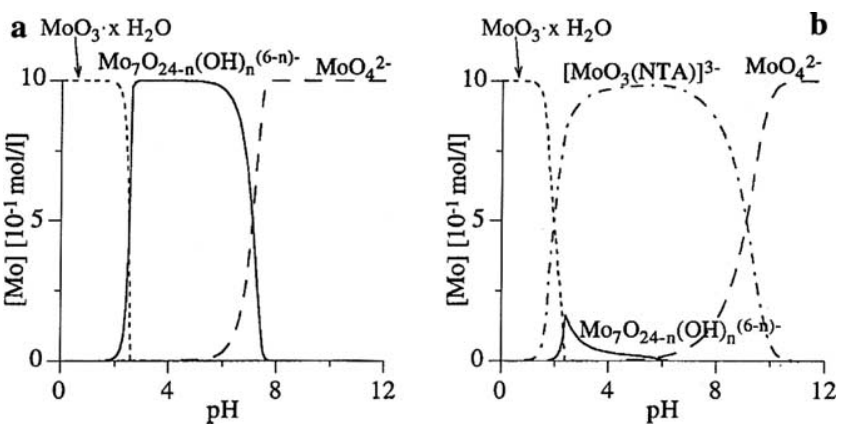

(A)
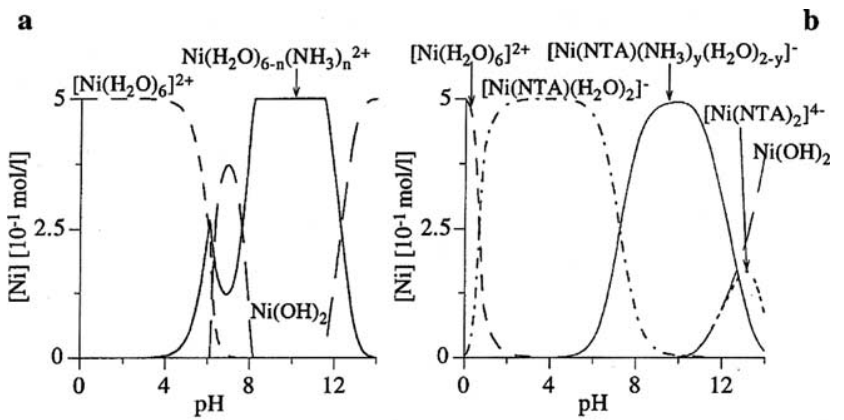

(B)
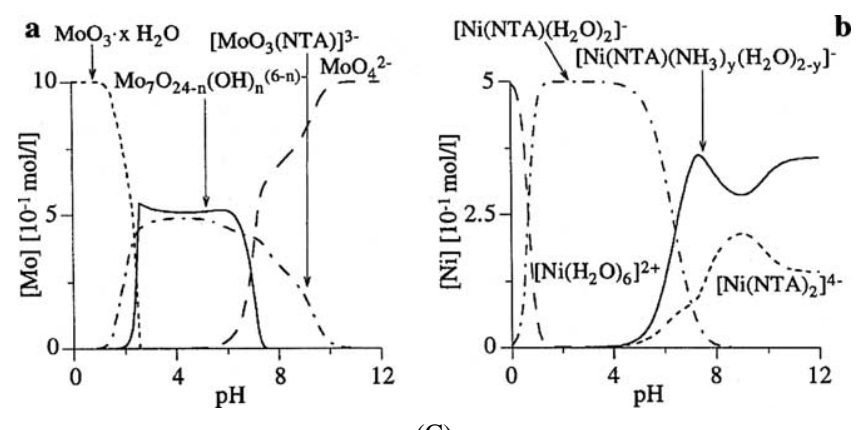

(C)

Fig. 2. Thermodynamic predictions of $\mathrm{Mo}, \mathrm{Ni}$, and $\mathrm{Mo}+\mathrm{Ni}$ species in aqueous solutions, with and without NTA as a function of the $\mathrm{pH}$ (taken from [14]). (A) Mo species in aqueous solution with $[\mathrm{Mo}]_{\text {tot }}=1 \mathrm{~mol} / \mathrm{L}$ without (a) and with (b) one NTA equivalent. (B) Ni species in aqueous solution with $[\mathrm{Ni}]_{\text {tot }}=0.5 \mathrm{~mol} / \mathrm{L}$ and $\left[\mathrm{NH}_{3}\right]_{\text {tot }}=5 \mathrm{~mol} / \mathrm{L}$ without (a) and with (b) one NTA equivalent. (C) Mo species (a) and Ni species (b) in a combined aqueous solution with $\left[\mathrm{NH}_{3}\right]_{\mathrm{tot}}=5 \mathrm{~mol} / \mathrm{L},[\mathrm{Mo}]_{\text {tot }}=1 \mathrm{~mol} / \mathrm{L}$, and Ni:Mo:NTA $=0.5: 1: 1$.

a solid phase is avoided, due to which uniform distributions and high dispersions of the (precursor of the) active phase are favored $[7,15,16]$. We, therefore, propose that the beneficial effects of chelated metal precursors are based on two interdependent phenomena.

1. There is a rapid increase of the viscosity of the solution upon evaporation of the solvent. The enhanced viscosity inhibits redistribution of the impregnation solution during drying, thus favoring a uniform distribution of the active component over the support bodies.

2. The chelated metal precursor forms not a crystalline compound but rather a gel-like phase. Upon further drying this phase presumably interacts weakly but suffi-

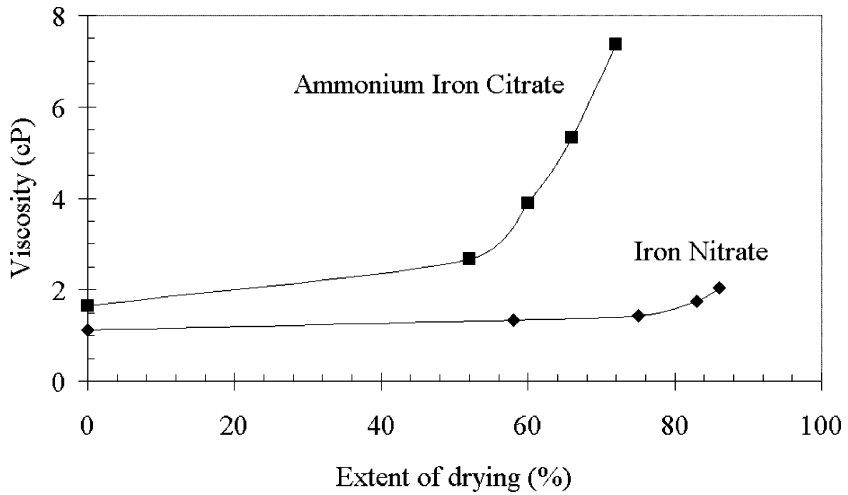

Fig. 3. Viscosity of solutions of ammonium iron(III)-citrate and of iron(III)-nitrate as a function of the extent of drying. The extent of drying of the starting solutions $(0.78 \mathrm{~mol} / \mathrm{L})$ is set at $0 \%$. $100 \%$ denotes completely dried.

ciently, through hydrogen bonding, with the support. The resulting so-called poorly crystallized compound is usually highly dispersed.

Pechini [17] and Marcilly et al. [18] recognized the suitability of aqueous solutions of chelated metal ions, usually citrates, as precursors for the production of nanometersize and homogeneously mixed oxides with controlled stoichiometry. To the chelate mixture ethylene glycol or another polyalcohol is added, and upon heating, polyesterification occurs, which leads to a homogeneous and viscous gel in which the metal ions are uniformly distributed. Upon further heating, excess solvent is removed and an intermediate resin is formed. Calcination of this resin at elevated temperatures results in removal of the organic residuals and formation of the mixed oxide powder [17,19]. As has been demonstrated by Choy and Han [20], the presence of a polyalcohol is not required to form the highly viscous phase. With only the chelated metal ions in solution, a viscous gel results upon drying and heating, too.

For aqueous solutions of ammonium iron(III)-citrate and iron(III)-nitrate Terörde measured the effect of solvent removal on the viscosity [21]. The results are shown in Fig. 3. Each concentration measured is presented as a particular stage of the drying process, with $0 \%$ being the solutions with an iron(III) concentration of $0.78 \mathrm{~mol} / \mathrm{L}$, and $100 \%$ indicating the situation of complete dryness. The figure shows that the viscosity of both solutions increases upon drying, with that of the ammonium iron citrate solution increasing more steeply.

When the two solutions are used as impregnates for the synthesis of silica supported iron(III)-oxide catalysts highly different results are obtained [21]. The support consisted of silica extrudates of $2.1 \mathrm{~mm}$ with a pore volume of $0.8 \mathrm{ml} / \mathrm{g}$ and a specific surface area of $44 \mathrm{~m}^{2} / \mathrm{g}$. With both solutions $(0.78 \mathrm{~mol} / \mathrm{L})$ a loading of $5 \mathrm{wt} \%$ was obtained. TEM micrographs (not shown) demonstrate that after drying and calcination with the citrate precursor a highly dispersed and well-distributed iron(III)-oxide phase (particle size, 2 to 
$5 \mathrm{~nm}$ ) was obtained. The nitrate precursor, on the other hand, gave rise to the presence of oxide clusters (size, $>200 \mathrm{~nm}$ ) of both small and large iron oxide particles, next to the support. This difference in results mainly can be ascribed to the difference in viscosity during drying. To support this statement we will survey the results obtained with a selected number of studies on model systems.

\section{Model studies on impregnation with metal chelates}

A very fruitful experimental study to gain more insight into the convenient behavior of solutions of metal chelates with regard to impregnation has been executed by Terörde [21]. His study aimed at the improvement of the iron dispersion in the oxidic precursor of the current Superclaus catalyst, i.e., $\mathrm{Fe}_{2} \mathrm{O}_{3}$ on silica. In a $\mathrm{H}_{2} \mathrm{~S} / \mathrm{O}_{2}$ flow (excess oxygen), this precursor is gradually transformed into supported iron(II)-sulfate, over which, with a selectivity of around $99 \%, \mathrm{H}_{2} \mathrm{~S}$ is directly oxidized to elemental sulfur and water. For a high catalytic activity a high dispersion is required [22].

Terörde performed his experiments with a non-porous model support. For this purpose silicon (100) wafers, provided with a hydrophilic, amorphous oxidic surface layer, were used, prepared via a procedure as described by Van Wijk et al. [23], onto which the precursor solutions were applied by spincoating at a speed of $4000 \mathrm{rpm}$. For characterization the wafers were dried at 60 and $120^{\circ} \mathrm{C}$ and calcined at $350{ }^{\circ} \mathrm{C}$, at which temperature all precursors used were converted into $\mathrm{Fe}_{2} \mathrm{O}_{3}$.

Although the structure of the thin oxidic surface layer will differ from that of a real amorphous silica support, it can be assumed that they are comparable. The capillary forces in real supports are not operative in the case of a flat surface, but if the support is spun during coating and drying, the centrifugal forces become the substitute for the capillary forces [23]. Because of the flatness and electrical conductivity of these model catalysts, techniques such as XPS and AES, and also AFM and STM, can very well be applied. In addition, it should be noted that with dry impregnation the ultimate loading only depends on the salt concentration of the impregnate, whereas with spincoating, the deposited amount per unit surface area depends on the initial concentration of the precursor solution, the liquid film height, the viscosity, the density, the evaporation rate of the solution, and the spinning frequency. Furthermore, due to the spinning process an appreciable amount of precursor solution is swept away from the wafer. For these reasons the ultimate loading obtained with impregnation differs from that with spincoating, even when precursor solutions are used with the same concentrations.

In Fig. 4 AFM graphs of silicon wafers, spincoated with various iron precursor salts, are shown. The vertical dimensions as established by AFM are taken as a reliable measure of particle sizes. In Table 1 a summary of the results of these spincoating experiments is presented. The amounts of deposited iron were determined by RBS. The trend in particle size obtained with the sulfate, chloride, and nitrate solutions follows the trend obtained with silica extrudates [21], as earlier reported by Van den Brink et al. [22], although large crystallites or clusters of smaller particles, the formation of which is related to migration through the pore system during drying, were not found here. Most striking is the difference between the results obtained with the citrate salt on the one and with the other salts on the other hand. With citrate, an almost perfectly flat film was observed. Especially when the relatively high concentration of ammonium iron citrate is taken into account, this is rather surprising. Explanation for this phenomenon can be found in the relatively high viscosity of the citrate solution, especially shortly before dryness, as indicated in Fig. 3.

\section{Mesoporous supports}

Recently, the application of active phases using aqueous chelated metal precursors was extended to mesoporous materials by Lensveld et al. [24,25]. It was shown that nickel (loading, $10 \mathrm{wt} \%$ ) could suitably be applied onto the ordered mesoporous material MCM-41 with nickel citrate as a precursor. The obtained results indicated that upon calcination, a much better dispersion of nickel oxide was obtained than with a nickel nitrate solution as precursor. Moreover, the average particle size as well as the particle size distribution were much smaller for the catalysts prepared with the chelated precursor, as can be seen in Fig. 5. Apparently, upon drying, the nickel nitrate precursor had been entrained with the flow of solvent, resulting in the precipitation of large nickel nitrate crystallites outside the support mesopores. However, it cannot be excluded that calcination of the nitrate precursor also contributes to some extent to the agglomeration of nickel oxide. In contrast, when a solution of chelated nickel precursor was used for impregnation, a thin film of nickel citrate became confined inside the mesopores, most likely due to an increase of the viscosity upon drying. This film presumably was formed by a weak but sufficiently strong interaction with the pore surface, i.e., via hydrogen bonding, and consequently covered the pore walls with a thin, uniform layer of precursor material. Subsequent calcination yielded a homogeneous distribution of exclusively small nickel oxide particles inside the mesopores. It should be noted here that the combustion of chelating ligands during calcination generally gives rise to a large adiabatic rise in temperature. However, it was found that the MCM-41 support material was perfectly able to withstand these high temperatures, since its characteristic textural and structural properties had been completely retained upon calcination. 

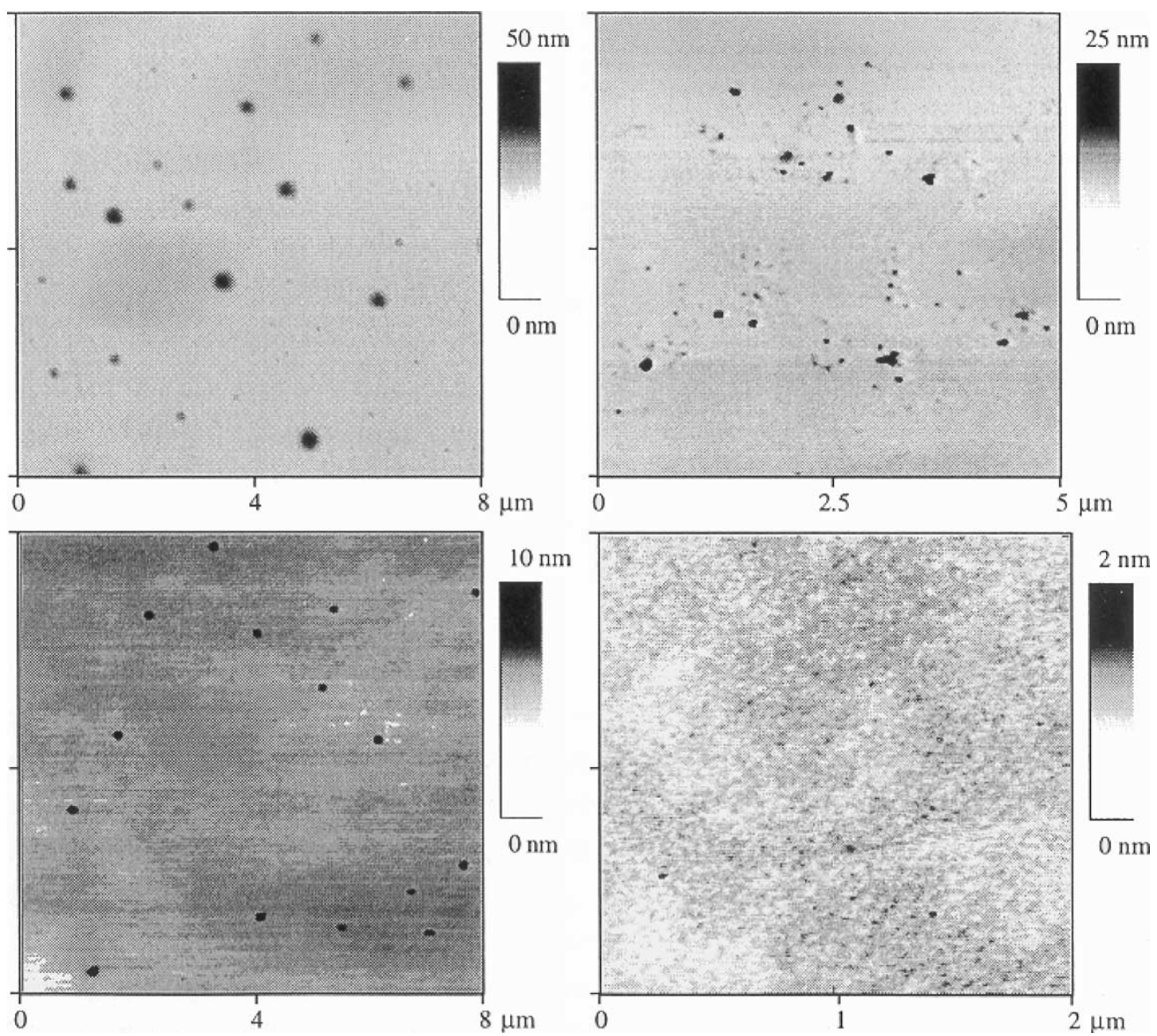

Fig. 4. AFM graphs of silicon wafers spincoated with solutions of ammonium iron(II)-sulfate (upper left), iron(III)-chloride (upper right), iron(III)-nitrate (lower left), and ammonium iron(III)-citrate (lower right). All graphs taken after calcinations.

\section{Hydrotreating catalysts}

In industry hydrotreating processes, which comprise HDS, HDN, hydrodemetallation, and aromatics hydrogenation, make use of supported molybdenum and tungsten catalysts promoted with cobalt or nickel. The active phase consists of small $\mathrm{MoS}_{2}$ slabs with the promotor ions dispersed over the edges, the so-called "CoMoS" phase (e.g., [26-29]). Recently, the wish to produce less-polluting transportation fuels, especially diesel, has been a strong incentive to the development of more active HDS catalysts. Chelating agents have played (and still play) a major role in this field of research [14,26-50].

The first use of a chelating agent (viz. NTA) in the design of silica-supported nickel- and cobalt-promoted molybdenum-based hydrotreating catalysts was patented by Thompson [43]. Thereupon it was reported by Van Veen et al. that catalyst preparation with a chelated cobalt-NTA precursor complex yielded catalysts containing exclusively the catalytically active CoMoS phase, whereas catalyst preparation without NTA resulted in a mixture of catalytically less active phases [30]. Cattaneo et al. showed that this advan-

Table 1

Summary of results of spincoating with solutions of various iron salts

\begin{tabular}{lccc}
\hline Precursor & Concentration $(\mathrm{mol} / \mathrm{L})$ & Amount deposited $^{\mathrm{a}}\left(\times 10^{15}{\left.\text { atoms } / \mathrm{cm}^{2}\right)}^{-5}\right.$ & Average particle size $^{\mathrm{b}}(\mathrm{nm})$ \\
\hline Ammonium iron sulfate & $7.9 \times 10^{-5}$ & 0.06 & 25 \\
Iron chloride & $1.26 \times 10^{-4}$ & 0.15 & 15 \\
Iron nitrate & $5.9 \times 10^{-6}$ & 0.07 & 7 \\
Ammonium iron citrate & $8.06 \times 10^{-3}$ & 4.90 & - \\
\hline
\end{tabular}

\footnotetext{
a Determined with RBS.
}

b Determined with AFM. 

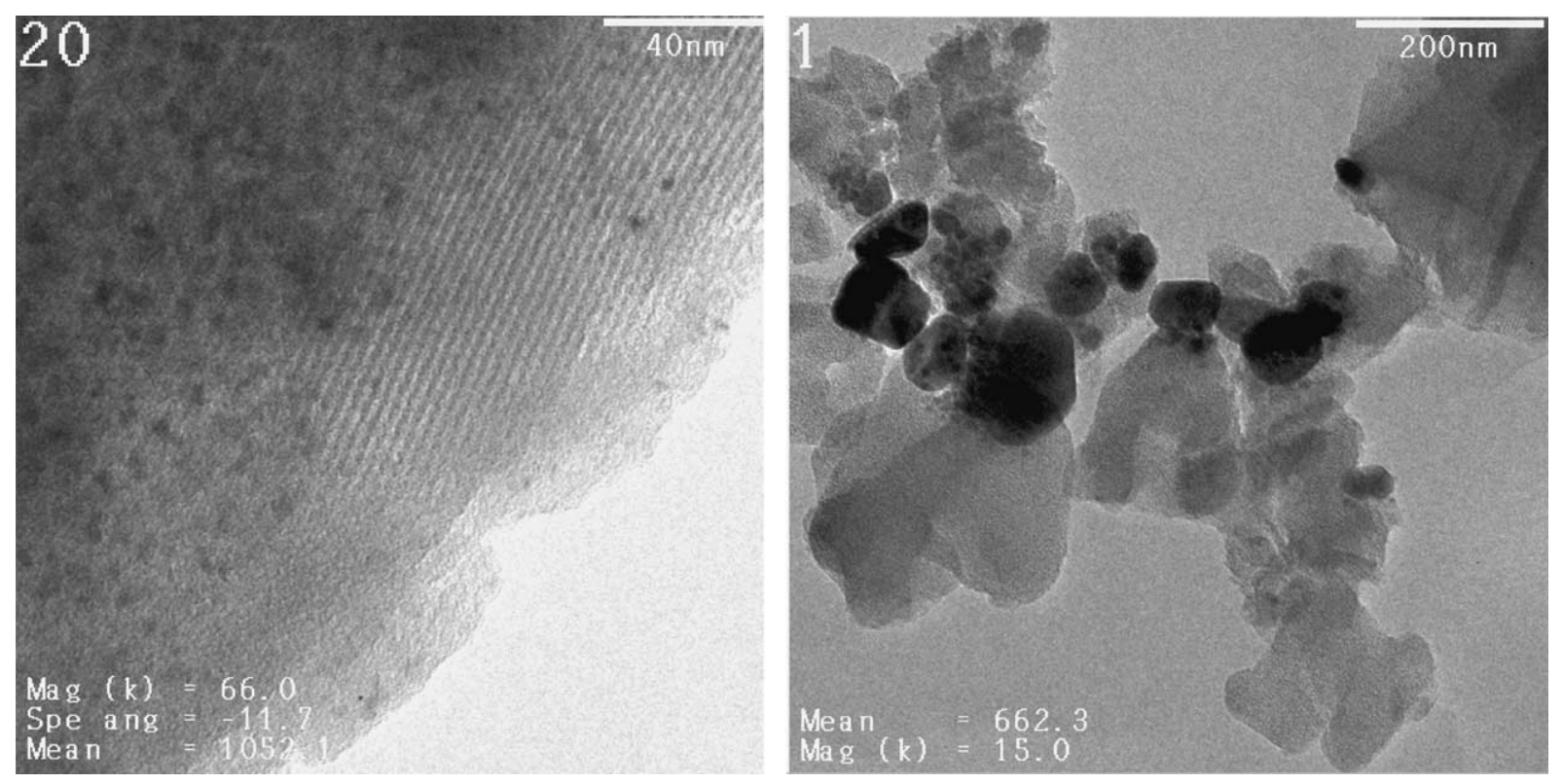

Fig. 5. MCM-41-supported nickel oxide catalysts prepared with a chelated nickel citrate precursor (left) and a nickel nitrate precursor (right). In the left TEM image the small nickel oxide particles, situated inside the MCM-41 mesopores, are clearly visible, whereas very large nickel oxide crystallites are present on the other catalyst.

tageous effect was not restricted to NTA, but that a wide range of chelating agents was able to direct the formation of the CoMoS phase [31]. A number of (model) studies have been aimed at the elucidation of the processes by which chelating agents influence the generation of the active phase [32-42]. The techniques used for this purpose were mainly XPS [32-39] and (Quick) EXAFS [40-42].

de Jong et al. [32,33] and Coulier et al. [34] studied the sulfidation behaviour of CoMo model catalysts supported by wafers onto which a thin layer of silica or alumina had been applied. The active phase was loaded onto these wafers by means of spincoating, a technique mimicking the incipient wetness impregnation technique for real catalysts. A model catalyst with chelating ligands was prepared from a solution containing both NTA and Co- and Mo-precursor. This catalyst was only dried prior to sulfidation. As a reference a model catalyst without chelating ligands was spincoated, dried, and calcined. After sulfidation (with $\mathrm{H}_{2} \mathrm{~S} / \mathrm{H}_{2}$ ) at different temperatures the wafer catalysts were transported to the XPS, thereby avoiding contact with air. The results of these measurements are given in Fig. 6. In the middle spectrum it is seen that sulfidation of the molybdenum precursor takes place at temperatures between 75 and $175{ }^{\circ} \mathrm{C}$. This temperature range was the same for both catalysts. In the dried catalyst prepared with NTA the cobalt precursor started to sulfide at temperatures exceeding $125^{\circ} \mathrm{C}$, which was completed only at a temperature of about $225^{\circ} \mathrm{C}$ (right spectrum). The consequence of this order of sulfidation is that $\mathrm{MoS}_{2}$ slabs have already been formed at the temperatures where the cobalt precursor sulfides. As a result the cobalt ions are able to disperse themselves over the edges of the $\mathrm{MoS}_{2}$ slabs during sulfidation, thus generating the CoMoS active phase. A strikingly different result was ob- tained when catalyst preparation was performed without NTA. Cobalt sulfidation starts already at ambient temperatures and is completed before $150{ }^{\circ} \mathrm{C}$ (left spectrum). This reversal of sulfidation order implies that at the temperatures where cobalt sulfides, $\mathrm{MoS}_{2}$ slabs have not yet formed. As a result cobalt sulfides into bulk $\mathrm{Co}_{9} \mathrm{~S}_{8}$, which is not able to redisperse over the $\mathrm{MoS}_{2}$ slabs at higher temperatures. As a consequence the CoMoS phase is formed to a small extent only.

In conclusion, the stability of $\mathrm{Co}^{2+}$ ions complexed by a chelating agent is greatly enhanced compared to $\mathrm{Co}^{2+}$ in a cobalt oxide environment. This effect is present until the chelating ligands are decomposed at elevated temperatures. As a result the presence of chelating agents retards the sulfidation of cobalt to sufficiently high temperatures to allow for the formation of the catalytically active CoMoS phase. Qualitatively similar results were obtained for a number of other (both wafer and extrudate supported) hydrotreating catalysts, in the presence of a variety of chelating agents, viz. $\mathrm{NiMo} / \mathrm{SiO}_{2}[35,40,41], \mathrm{NiMo} / \mathrm{Al}_{2} \mathrm{O}_{3}$ [42], $\mathrm{NiW} / \mathrm{SiO}_{2}$ [36,37], $\mathrm{CoW} / \mathrm{SiO}_{2}$ [38], $\mathrm{NiW} / \mathrm{Al}_{2} \mathrm{O}_{3}$ [39], and $\mathrm{CoW} / \mathrm{Al}_{2} \mathrm{O}_{3}$ [39].

\section{Survey}

Various research efforts over the years have demonstrated that solutions of chelated metal ions provide excellent precursors for the preparation of heterogeneous catalysts by means of incipient wetness impregnation using a multitude of oxidic support materials. In Table 2 we present a short survey of reported catalyst preparations making use of chelated metal ion precursors. The increasing viscosity of 

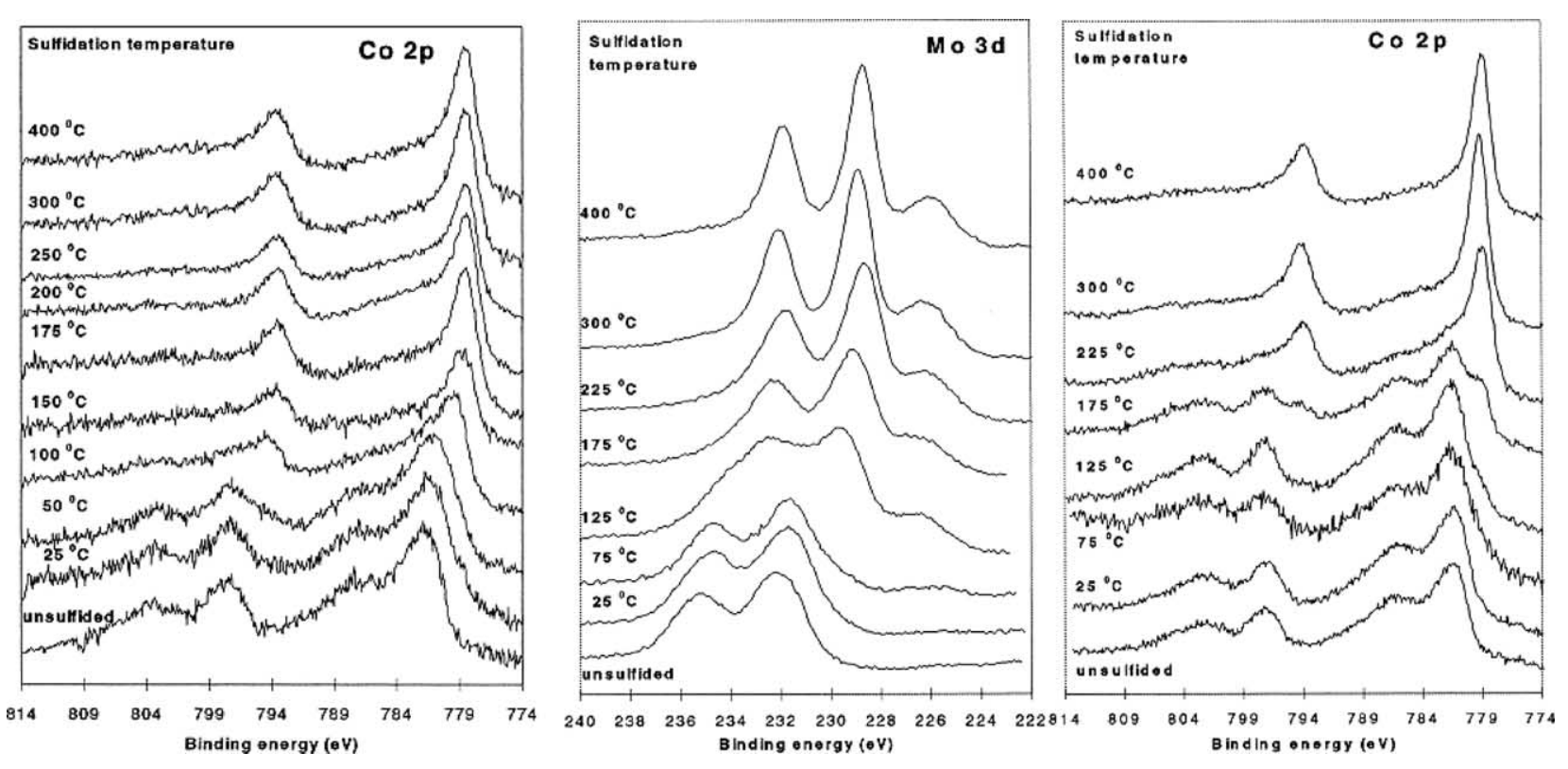

Fig. 6. XPS spectra of wafer-supported (silica) CoMo catalysts prepared with and without NTA after sulfidation $\left(\mathrm{H}_{2} \mathrm{~S} / \mathrm{H}_{2}\right)$ at various temperatures. (Left): Co $2 p$ edge of a catalyst prepared without chelating agent. (Middle and right): Mo 3d and Co $2 p$ edge of a catalyst prepared with NTA. (Spectra taken from [50].)

solutions of chelated metal ions during drying and the filmforming abilities of these precursors on the support materials result, upon calcination, in homogeneous distributions and high dispersions of the desired metal oxides. Because of the relatively weak interaction with the support, many of these oxides can be converted into the metal phase by reduction at low temperatures in a hydrogen flow, generally without significant loss of dispersion.

\section{Concluding remarks}

Aqueous solutions of metal chelates appear highly suitable for the production of supported metal and metal oxide

Table 2

Elements which have successfully been applied onto support materials as chelated complexes to produce heterogeneous catalysts with very small metal (oxide) particles and homogeneous distributions

\begin{tabular}{lllc}
\hline Element & \multicolumn{1}{c}{ Support } & \multicolumn{1}{c}{ Chelating ligand } & Reference \\
\hline $\mathrm{Co}$ & $\gamma-\mathrm{Al}_{2} \mathrm{O}_{3}$ & Citrate, EDTA & Van de Loosdrecht [51] \\
& $\mathrm{ZrO}_{2}$ & EDTA & Boot [52] \\
$\mathrm{Cr}$ & $\mathrm{SiO}_{2}$ & EDTA & Van den Brink [53] \\
$\mathrm{Cu}$ & $\gamma-\mathrm{Al}_{2} \mathrm{O}_{3}$ & EDTA & Tijburg [54] \\
& $\mathrm{Silica}$-wafer & Acetate & Van Wijk [55] \\
& $\mathrm{Silica}$-wafer & Salicylaldehyde & Van Wijk [23] \\
& $\mathrm{SiO}_{2}$ & Citrate & E. de Wit [54] \\
$\mathrm{Fe}$ & $\mathrm{SiO}_{2}$ & Citrate, EDTA, gluconate & Van den Brink [22] \\
$\mathrm{La}$ & $\gamma-\mathrm{Al}_{2} \mathrm{O}_{3}$ & EDTA & Tijburg [56] \\
$\mathrm{Mn}$ & $\gamma-\mathrm{Al}_{2} \mathrm{O}_{3}$ & Citrate, EDTA & Van de Kleut [54] \\
& $\mathrm{ZrO}_{2}$ & EDTA & Boot [52] \\
$\mathrm{Ni}$ & $\mathrm{SiO}_{2}$ & Citrate & Takahashi [57] \\
& $\mathrm{SiO}_{2}$ & EDTA & Van Yperen [54] \\
$\mathrm{Sn}$ & $\alpha-\mathrm{Al}_{2} \mathrm{O}_{3}$ & Citrate, EDTA, formate & Meima [8] \\
$\mathrm{Zn}$ & $\mathrm{SiO}_{2}$ & Citrate & Terörde [58] \\
$\mathrm{Zr}$ & $\alpha-\mathrm{Al}_{2} \mathrm{O}_{3}$ & Citrate & E. Stobbe [54] \\
\hline
\end{tabular}

catalysts by impregnation. Upon drying, the increase in viscosity of such solutions circumvents redistribution of the catalyst precursor while the formation of a gel-like film over the support surface favors, upon calcination, homogeneous distributions and high dispersions of the formed oxides.

In conclusion, we have shown that the use of chelated metal precursors in the preparation of heterogeneous catalysts has significantly contributed to important catalytic developments:

- The invention of the Superclaus process and the catalysts associated with this process for the abatement of polluting $\mathrm{SO}_{2}$ emissions (responsible for acid rain).

- The preparation of improved hydrotreating catalysts and the elucidation of the mechanism by which the chelated precursors direct the formation of the catalytically active phase.

- The preparation of a new class of catalysts supported by ordered mesoporous materials.

Finally, a literature survey of a wide range of metalsupport systems is presented to further emphasize and illustrate the suitability of the method, also for academic catalyst research.

\section{References}

[1] J.R. Anderson, Structure of Metallic Catalysts, Academic Press, London, 1975.

[2] J.W. Geus, J.A.R. van Veen, in: R.A. van Santen, P.W.N.M. van Leeuwen, J.A. Moulijn, B.A. Averill (Eds.), Catalysis. An Integrated 
Approach, Second Revised and Enlarged Edition, Elsevier, Amsterdam, 1999, p. 459.

[3] (a) M. Che, in: L. Guczi, F. Solymosi, P. Tétényi (Eds.), New Frontiers in Catalysis, Elsevier, Amsterdam, 1993, p. 31;

(b) J.Y. Carriat, M. Che, M. Kermarec, M. Verdaguer, A. Michalowicz, J. Am. Chem. Soc. 120 (1998) 2059;

(c) F. Negrier, E. Marceau, M. Che, Chem. Commun. (2002) 1194.

[4] K.P. de Jong, Curr. Opin. Solid State Mater. Sci. 4 (1999) 55.

[5] J.W. Geus, Stud. Surf. Sci. Catal. 16 (1983) 1.

[6] K.P. de Jong, Stud. Surf. Sci. Catal. 63 (1991) 19.

[7] N. Kotter, L. Riekert, Stud. Surf. Sci. Catal. 3 (1978) 51.

[8] G.R. Meima, B.G. Dekker, A.J. van Dillen, J.W. Geus, J.E. Bongaarts, F.R. van Buren, K. Delcour, J.M. Wigman, Stud. Surf. Sci. Catal. 31 (1987) 83.

[9] W.W. Porterfield, Inorganic Chemistry, Academic Press, New York, 1993.

[10] T.W. Swaddle, Inorganic Chemistry, Academic Press, New York, 1997.

[11] P. Prapaipong, E.L. Shock, Geochim. Cosmochim. Acta 65 (2001) 3931.

[12] G. Schwartzenbach, Die komplexometrische Titration, Ferdinand Enke, Stuttgart, 1955.

[13] A.E. Martell, R.D. Hancock, Metal Complexes in Aqueous Solutions, Plenum, New York, 1996.

[14] L. Medici, R. Prins, J. Catal. 163 (1996) 28.

[15] L.M. Knijff, P.H. Bolt, R. van Yperen, A.J. van Dillen, J.W. Geus, Stud. Surf. Sci. Catal. 63 (1990) 165.

[16] L.M. Knijff, PhD thesis, Utrecht University, The Netherlands, 1993.

[17] M.P. Pechini, US Patent 3,330,697 (1967).

[18] C. Marcilly, P. Courty, B. Delmon, J. Am. Ceram. Soc. 53 (1970) 36.

[19] C. Laberty-Robert, F. Ansart, C. Deloget, M. Gaudon, A. Rousset, Mater. Res. Bull. 36 (2001) 2083.

[20] J.-H. Choy, Y.-S. Han, Mater. Lett. 32 (1997) 209.

[21] R.J.A.M. Terörde, PhD thesis, Utrecht University, The Netherlands, 1996.

[22] P.J. van den Brink, A. Scholten, A. van Wageningen, M.D.A. Lamers, A.J. van Dillen, J.W. Geus, Stud. Surf. Sci. Catal. 63 (1991) 527.

[23] R. van Wijk, O.L.J. Gijzeman, J.W. Geus, E. ten Grotenhuis, J.V. van Miltenburg, Catal. Lett. 24 (1994) 171.

[24] D.J. Lensveld, J.G. Mesu, A.J. van Dillen, K.P. de Jong, Microporous Mesoporous Mater. 44-45 (2001) 401.

[25] D.J. Lensveld, J.G. Mesu, A.J. van Dillen, K.P. de Jong, Stud. Surf. Sci. Catal. 143 (2002) 647.

[26] S.M.A.M. Bouwens, D.C. Koningsberger, V.J.H. de Beer, S.P.A. Louwers, R. Prins, Catal. Lett. 5 (1990) 273.

[27] S.M.A.M. Bouwens, J.A.R. van Veen, D.C. Koningsberger, V.H.J. de Beer, R. Prins, J. Phys. Chem. 95 (1991) 123.

[28] S.P.A. Louwers, R. Prins, J. Catal. 133 (1992) 94.

[29] S.M.A.M. Bouwens, F.B.M. van Zon, M.P. van Dijk, A.M. van der Kraan, V.H.J. de Beer, J.A.R. van Veen, D.C. Koningsberger, J. Catal. 146 (1994) 375.

[30] J.A.R. van Veen, E. Gerkema, A.M. van der Kraan, P.A.J.M. Hendriks, H. Beens, J. Catal. 133 (1992) 112.
[31] R. Cattaneo, T. Shido, R. Prins, J. Catal. 185 (1999) 199.

[32] A.M. de Jong, V.H.J. de Beer, J.A.R. van Veen, J.W. Niemantsverdriet, J. Phys. Chem. 100 (1996) 17722.

[33] A.M. de Jong, V.H.J. de Beer, J.A.R. van Veen, J.W. Niemantsverdriet, Stud. Surf. Sci. Catal. 106 (1997) 273.

[34] L. Coulier, V.H.J. de Beer, J.A.R. van Veen, J.W. Niemantsverdriet, Top. Catal. 13 (2000) 99.

[35] L. Coulier, V.H.J. de Beer, J.A.R. van Veen, J.W. Niemantsverdriet, J. Catal. 197 (2001) 26.

[36] G. Kishan, L. Coulier, V.H.J. de Beer, J.A.R. van Veen, J.W. Niemantsverdriet, Chem. Commun. (2000) 1103.

[37] G. Kishan, L. Coulier, V.H.J. de Beer, J.A.R. van Veen, J.W. Niemantsverdriet, J. Catal. 196 (2000) 180.

[38] G. Kishan, L. Coulier, J.A.R. van Veen, J.W. Niemantsverdriet, J. Catal. 200 (2001) 194.

[39] L. Coulier, G. Kishan, J.A.R. van Veen, J.W. Niemantsverdriet, J. Phys. Chem. B 106 (2002) 5897.

[40] L. Medici, R. Prins, J. Catal. 163 (1996) 38.

[41] R. Cattaneo, T. Weber, T. Shido, R. Prins, J. Catal. 191 (2000) 225.

[42] R. Cattaneo, F. Rota, R. Prins, J. Catal. 199 (2001) 318.

[43] M.S. Thompson, European Patent 0181035, assigned to Shell Int. Research, 1986.

[44] J.A.R. van Veen, E. Gerkema, A.M. van der Kraan, A. Knoester, J. Chem. Soc. Chem. Commun. 1684 (1987).

[45] J.A.R. van Veen, H.A. Colijn, P.A.J.M. Hendriks, A.J. van Welsenes, Fuel Proc. Technol. 35 (1993) 137.

[46] K. Hiroshima, T. Mochizuki, T. Honma, T. Shimizu, M. Yamada, Appl. Surf. Sci. 121/122 (1997) 433.

[47] K. Inamura, K. Uchikawa, S. Matsuda, Y. Akai, Appl. Surf. Sci. 121/122 (1997) 468.

[48] T. Shimizu, K. Hiroshima, T. Honma, T. Mochizuki, M. Yamada, Catal. Today 45 (1998) 271.

[49] Y. Ohta, T. Shimizu, T. Honma, M. Yamada, Stud. Surf. Sci. Catal. 127 (1999) 161.

[50] L. Coulier, PhD thesis, Eindhoven University of Technology, The Netherlands, 2001.

[51] J. van de Loosdrecht, M. van der Haar, A.M. van der Kraan, A.J. van Dillen, J.W. Geus, Appl. Catal. A 150 (1997) 365.

[52] L.A. Boot, M.H.J.V. Kerkhoffs, B.Th. van der Linden, A.J. van Dillen, J.W. Geus, F.R. van Buren, Appl. Catal. A 137 (1996) 69.

[53] P.J. van den Brink, J.W. Geus, European Patent 0409353, assigned to VEG Gasinstituut NV and Comprimo BV, 1991.

[54] A.J. van Dillen, J.W. Geus, et al., unpublished results.

[55] E. ten Grotenhuis, J.C. van Miltenburg, J.P. van der Eerden, R. van Wijk, O.L.J. Gijzeman, J.W. Geus, C.H.M. Marée, Catal. Lett. 28 (1994) 109.

[56] I.I.M. Tijburg, J.W. Geus, H.W. Zandbergen, J. Mater. Sci. 26 (1991) 6479.

[57] R. Takahashi, S. Sato, T. Sodesawa, M. Kato, S. Takenaka, S. Yoshida, J. Catal. 204 (2001) 259.

[58] R.J.A.M. Terörde, J.W. Geus, WO Patent 9,732,813 and US Patent $6,207,127$, assigned to Gastec NV and Stork Engineers and Contractors BV, 2001. 